\title{
Level-Specific Differences in Systemic Expression of Pro- and Anti-Inflammatory Cytokines and Chemokines after Spinal Cord Injury
}

\author{
James Hong ${ }^{1,2}$, Alex Chang ${ }^{1,2}$, Mohammad-Masoud Zavvarian ${ }^{1,2}$, Jian Wang ${ }^{1}$, Yang Liu ${ }^{1}$ \\ and Michael G. Fehlings 1,3 ,* \\ 1 Division of Genetics and Development, Toronto Western Research Institute, University Health Network, \\ Toronto, ON M5T 2S8, Canada; james.hong@live.com (J.H.); le.chang@mail.utoronto.ca (A.C.); \\ Mohammad.zavvarian@mail.utoronto.ca (M.-M.Z.); jianw@uhnres.utoronto.ca (J.W.); \\ Yang.Liu@uhnresearch.ca (Y.L.) \\ 2 Institute of Medical Science, University of Toronto, Toronto, ON M5S 1A8, Canada \\ 3 Spinal Program, University Health Network, Toronto Western Hospital, Toronto, ON M5T 2S8, Canada \\ * Correspondence: Michael.Fehlings@uhn.ca; Tel.: +1-416-603-5627
}

Received: 11 July 2018; Accepted: 23 July 2018; Published: 25 July 2018

\begin{abstract}
While over half of all spinal cord injuries (SCIs) occur in the cervical region, the majority of preclinical studies have focused on models of thoracic injury. However, these two levels are anatomically distinct-with the cervical region possessing a greater vascular supply, grey-white matter ratio and sympathetic outflow relative to the thoracic region. As such, there exists a significant knowledge gap in the secondary pathology at these levels following SCI. In this study, we characterized the systemic plasma markers of inflammation over time (1, 3, 7, 14, 56 days post-SCI) after moderate-severe, clip-compression cervical and thoracic SCI in a rat model. Using high-throughput ELISA panels, we observed a clear level-specific difference in plasma levels of VEGF, leptin, IP10, IL18, GCSF, and fractalkine. Overall, cervical SCI had reduced expression of both pro- and anti-inflammatory proteins relative to thoracic SCI, likely due to sympathetic dysregulation associated with higher level SCIs. However, contrary to the literature, we did not observe level-dependent splenic atrophy with our incomplete SCI model. This is the first study to compare the systemic plasma-level changes following cervical and thoracic SCI using level-matched and time-matched controls. The results of this study provide the first evidence in support of level-targeted intervention and also challenge the phenomenon of high SCI-induced splenic atrophy in incomplete SCI models.
\end{abstract}

Keywords: spinal cord injury; inflammation; plasma

\section{Introduction}

Traumatic spinal cord injury (SCI) - despite breakthroughs in pre-operative, surgical and post-operative care-continues to be a life-threatening injury, both acutely and chronically [1]. After primary mechanical injury, a dual-edged cascade of inflammatory and vascular events-collectively referred to as the secondary injury phase-ensues [2,3]. While it is difficult to determine the causative mechanism of secondary injury, several mechanisms including vascular disruption [4], glutamate excitoxicity [5,6], lipid peroxidation [7-9], blood-spinal-cord-barrier disruption [10-12] and ionic imbalance $[13,14]$ have been the focus of therapeutic targeting. The ultimate consequence of these events is apoptosis, neuronal and axonal death, and de/dys-myelination manifesting as grey and white matter loss at the injury epicenter [1].

Preclinical SCI studies thus far, driven by post-operative care requirements and ease-of-use, have most commonly employed thoracic SCI (tSCI) models despite the increased prevalence and incidence of 
cervical SCI (cSCI) [15]. A central rationale for specifically investigating CSCI models is the appreciation that critical anatomical differences exist between the cervical and thoracic spinal cord resulting in different pathophysiological responses to injury and treatment [16]. For instance, the cervical spine is composed of smaller vertebrae with increased mobility, has increased central and peripheral vascular supply and flow, a higher gray-white matter ratio, and contains the neural circuitry crucial for respiration, forelimb motion, and sympathetic outflow to the heart. Pathophysiologically, the cervical gray matter vasculature has less pericyte coverage than the thoracic cord, resulting in a blood spinal cord barrier (BSCB) predisposed to increased permeability [10]. Further, in high-thoracic transection models of SCI, removal of spinal sympathetic preganglionic neurons from supraspinal control results in autonomic dysreflexia [17]. This in turn has been shown to instigate immunosuppressive effects—-known as SCI-induced immune depression syndrome (SCI-IDS) — that stem directly from early splenocyte death and splenic atrophy due to acute and repeated chronic exposure to glucocorticoids and intrasplenic norepinephrine [18].

As cSCI has a direct neurological impact on cardiovascular function and peripheral immunity [19-21], we aimed to characterize the temporal profile (3-56 days) of vascular and inflammatory markers after $\mathrm{CSCI}$ and $\mathrm{tSCI}$ and elucidate any level-specific changes in their expression. Further, as robust spleen-mass changes were observed in the aforementioned transection studies on SCI-IDS, we also evaluated time and sham-normalized spleen-body weight ratios in our model.

\section{Results}

Of the 35 proteins surveyed in this study, 19 passed our initial filtering criteria, while 16 proteins that contained interpolated, extrapolated or out-of-range values were removed. All comparisons below are presented in order from thoracic to cervical.

\subsection{Level-Specific Differences in Plasma Protein Levels after Cervical and Thoracic Laminectomy}

To investigate whether there were baseline differences in the expression of any of these proteins after cervical and thoracic laminectomy, heat-mapping and statistical analyses of protein concentrations were carried out with naïve plasma shown as a reference (excluded from cluster analyses). Heat-mapping (Figure 1A) demonstrated several clusters of expression. While several proteins had trending differences (RANTES, $p=0.06$ at 14 days; LIX, $p=0.052$ at 14 days; and IL10, $p=0.068$ ), two proteins within cluster 5 showed significant differences in the expression of IP10 (56 days, $131.5 \pm 11.2$ vs. $450.3 \pm 15.8 \mathrm{pg} / \mathrm{mL}, p=0.003$ ) and IL18 ( 3 days, $745.1 \pm 84.8$ vs. $400.2 \pm 47.5 \mathrm{pg} / \mathrm{mL}, p=0.036$ ). The time-series expression of these three proteins is shown in Figure $1 \mathrm{~B}$.

\subsection{Level-Specific Differences in Plasma Protein Levels after Cervical and Thoracic SCI}

Of the 19 proteins analyzed (Figure 2), six showed significant differences at one or more time-points between time-matched, level-matched, laminectomy-normalized cSCI and tSCI groups (expressed as fold-change to laminectomy). The six proteins that showed level-specific differences were VEGF (day $7,-0.1 \pm 0.2$ vs. $1.325 \pm 0.1, p=0.03$ ), leptin (day $1,1.2 \pm 0.4$ vs. $-0.05 \pm 0.3$, $p=0.04$; day $56,-0.1 \pm 0.4$ vs. $-2.0 \pm 0.4, p=0.0009$ ), IP10 (day $1,0.3 \pm 0.3$ vs. $-0.7 \pm 0.04, p=0.02$; day $7,-0.891 \pm 0.3$ vs. $0.4 \pm 0.2, p=0.0005$; day $56,0.9 \pm 0.2$ vs. $-1.0 \pm 0.3, p<0.0001)$, IL18 (day $56,-1.5 \pm 0.3$ vs. $-0.05 \pm 0.4, p=0.02$ ), $\operatorname{GCSF}$ (day 7, $1.010 \pm 0.187$ vs. $3.943 \pm 1.663, p=0.006$ ), and fractalkine (day 1, $0.3 \pm 0.1$ vs. $-0.6 \pm 0.2, p=0.004$ ). Both of the proteins (IP10 and IL18) that showed level-specific baseline differences were significant after SCI. However, while differences in the 56-day baseline of IP10 contributed to a significant result, the 3-day baseline difference in IL18 did not. 
A

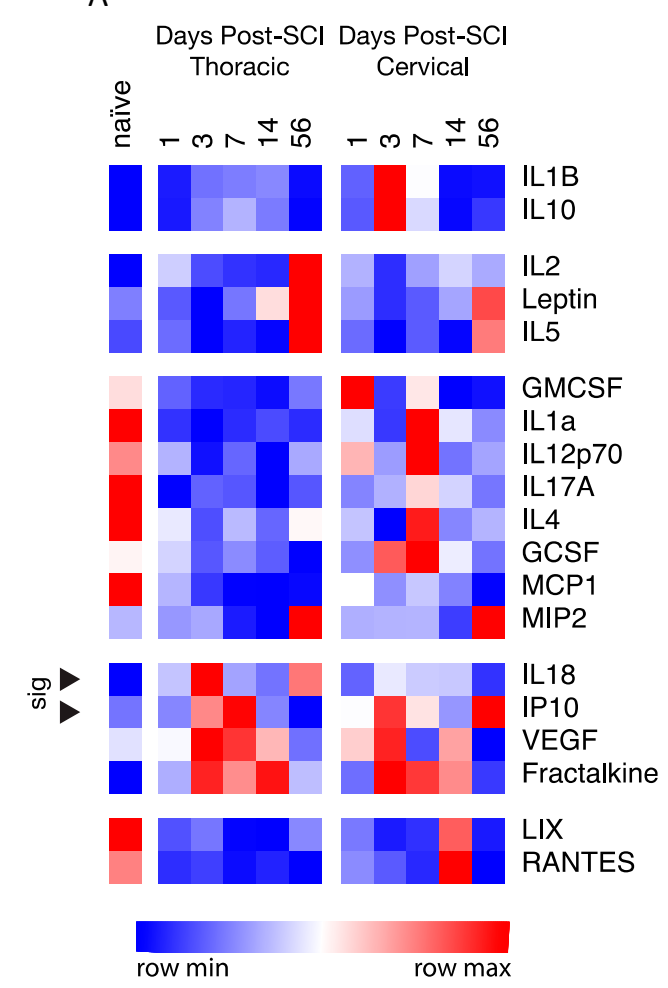

B

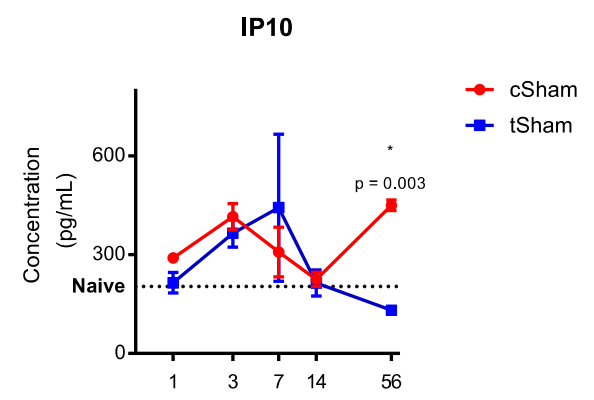

Days Post-Laminectomy

IL18

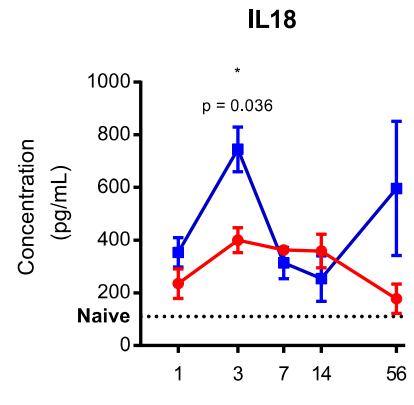

Days Post-Laminectomy

Figure 1. (A) Heat map and hierarchical cluster analyses reveal six clusters of temporal expression amongst cSham and tSham groups. Of the proteins analyzed, two proteins (marked with arrows) within cluster 4 reached statistical significance (IL18 and IP10). Naive data are shown as a baseline reference. Data are shown with relative color coding, with blue associated with the row minimum and red with the row maximum; all data are based on raw concentration in $\mathrm{pg} / \mathrm{mL}$; (B) Temporal expression of the two significant level-distinct proteins. Error bars represent SEM.

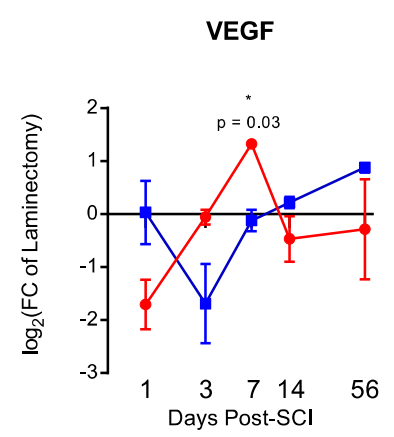

IL18

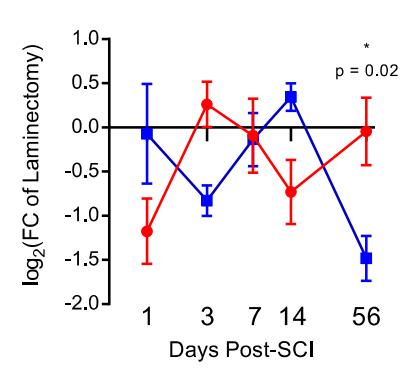

Leptin

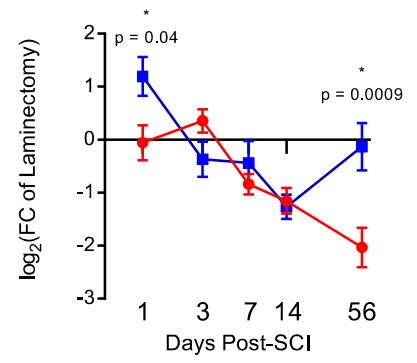

GCSF

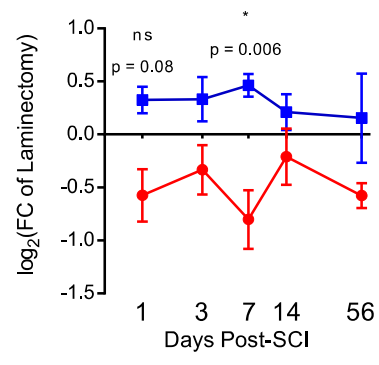

IP10

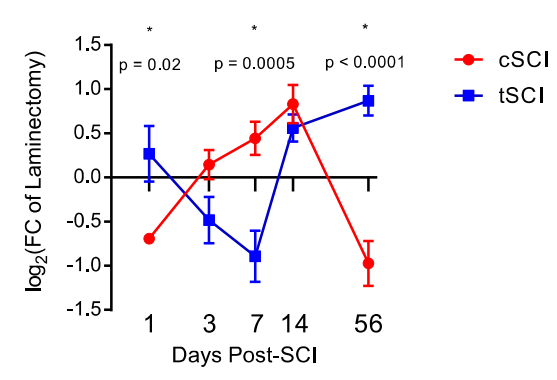

Fractalkine

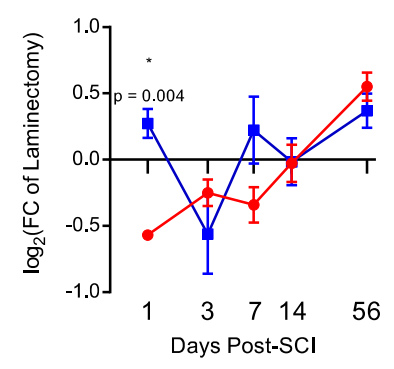

Figure 2. Temporal expression profile of the six significant differentially-expressed proteins: VEGF, leptin, IP10, IL18, GCSF and fractalkine. Error bars represent SEM. 


\subsection{Temporal Expression Patterns of Plasma Proteins after SCI}

To dissect the various temporal expression patterns after cSCI and tSCI, heatmap and $k$-means cluster analysis were performed (Figure 3). In tSCI, three main clusters were found with cluster 1 showing acute/chronic upregulation with subacute downregulation; cluster 2 showing an acute/subacute upregulation with chronic downregulation; and cluster 3 consisting of a single member showing constitutive upregulation. Similarly, in cSCI, three major clusters were defined with cluster 1 showing constitutive downregulation with some acute upregulation; cluster 2 showing proteins with acute/subacute downregulation with chronic upregulation; and cluster 3 showing proteins that had acute/subacute upregulation followed by chronic downregulation.
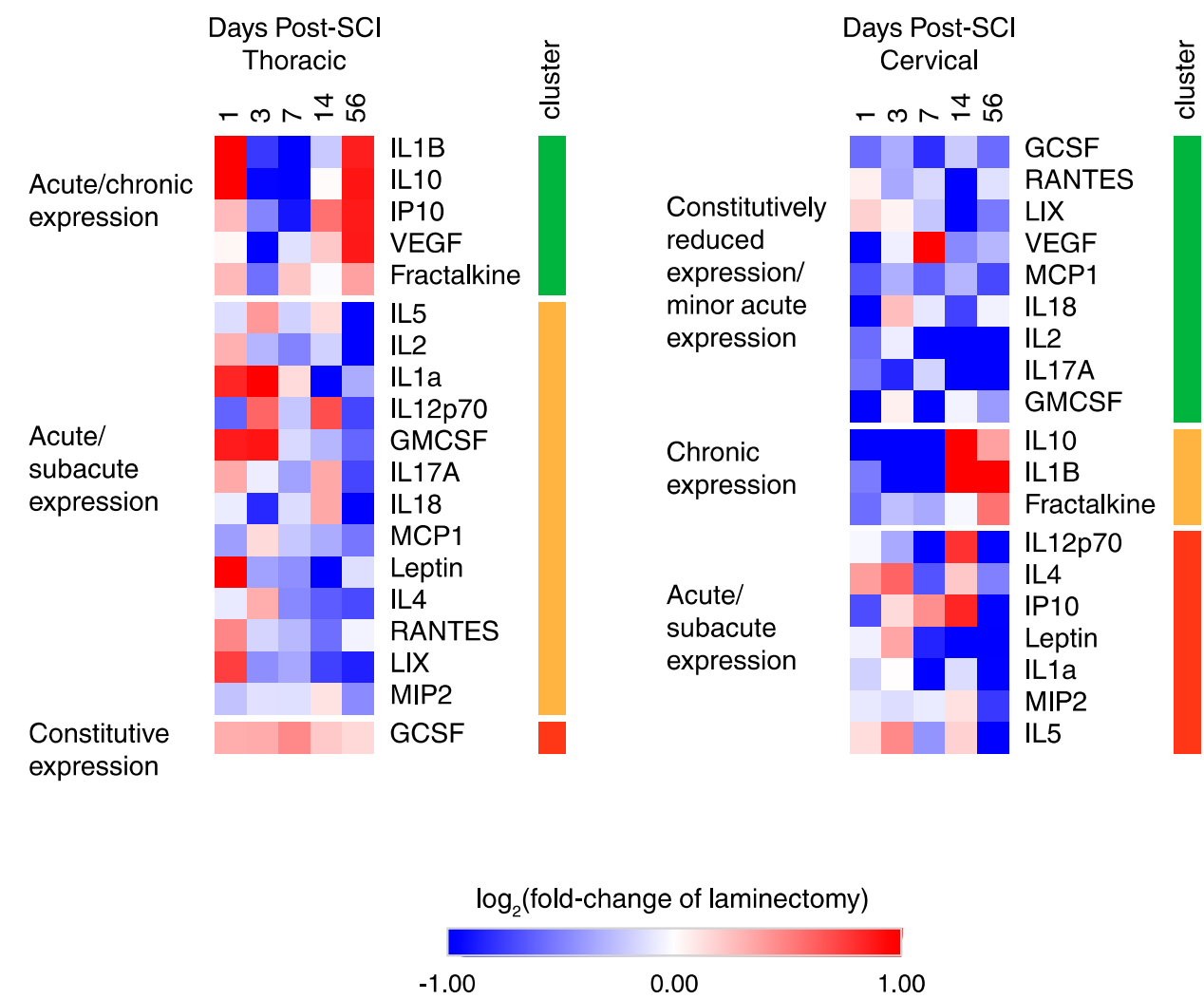

Figure 3. Heatmap and $k$-means clustering reveals three major clusters of temporal expression in cSCI and tSCI. Expression is displayed as log2 (fold-change of laminectomy) with blue indicating downregulation and red indicating upregulation.

\subsection{Functional Classification of Serum Protein after SCI}

Using several reviews and meta-analyses articles [22-29], pro-inflammatory and anti-inflammatory functions were assigned to each of the 19 proteins to survey the overall inflammatory status after CSCI and tSCI (Figure 4). It is evident that overall, tSCI has increased expression of both pro- and anti-inflammatory proteins over time compared to CSCI. While most of these proteins are strikingly upregulated in the acute phase of thoracic relative to cervical SCI, a few of these differences equilibrated chronically (e.g., IL1b, fractalkine, IL10).

\subsection{Spleen Weight}

To identify whether splenic atrophy was observed in our model of incomplete SCI, mass-normalized spleen weights were measured and expressed as a fold-change of time-matched laminectomized shams (Figure 5). While a decrease in weight between injured and time-matched laminectomized shams was seen in both cSCI and $\mathrm{tSCI}$, this did not reach statistical significance. 
However, a significant increase in spleen weight was observed between 3 and 14 days in cSCI $(0.862 \pm 0.078$ vs. $1.188 \pm 0.113, p=0.03)$, but only trended for tSCI $(p=0.06)$.

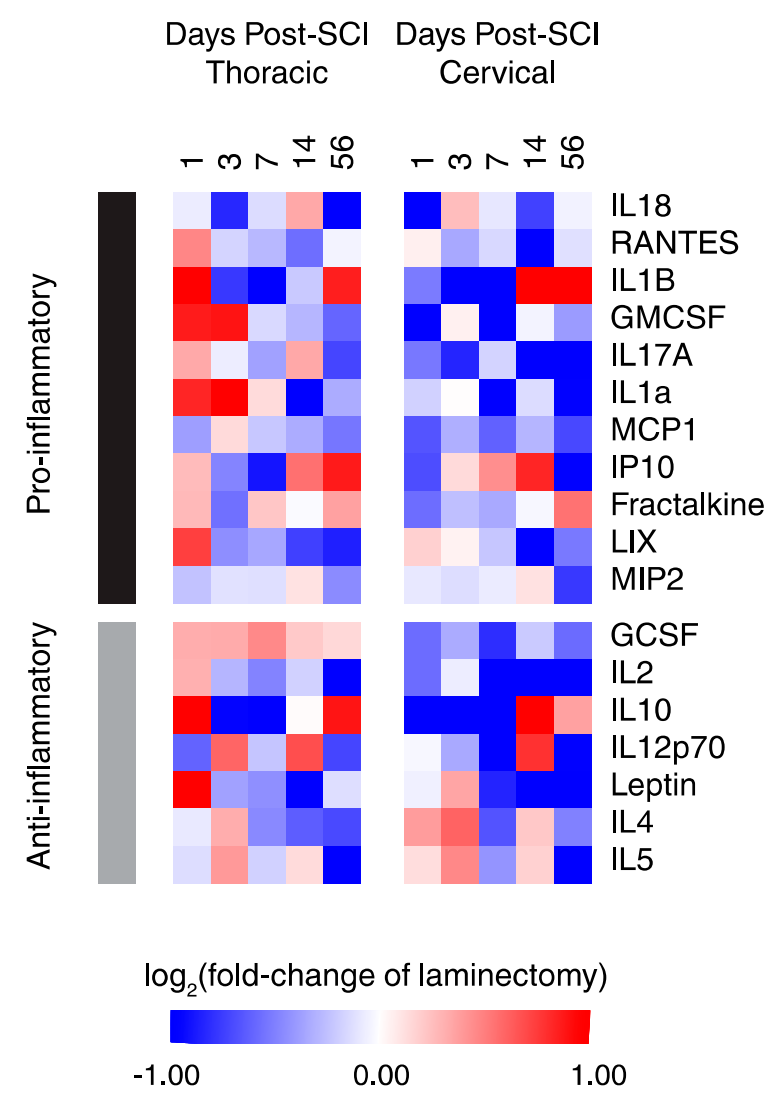

Figure 4. Heat map of functionally-segregated proteins after cSCI and tSCI. Expression is displayed as $\log 2$ (fold-change of laminectomy) with blue indicating downregulation and red indicating upregulation.

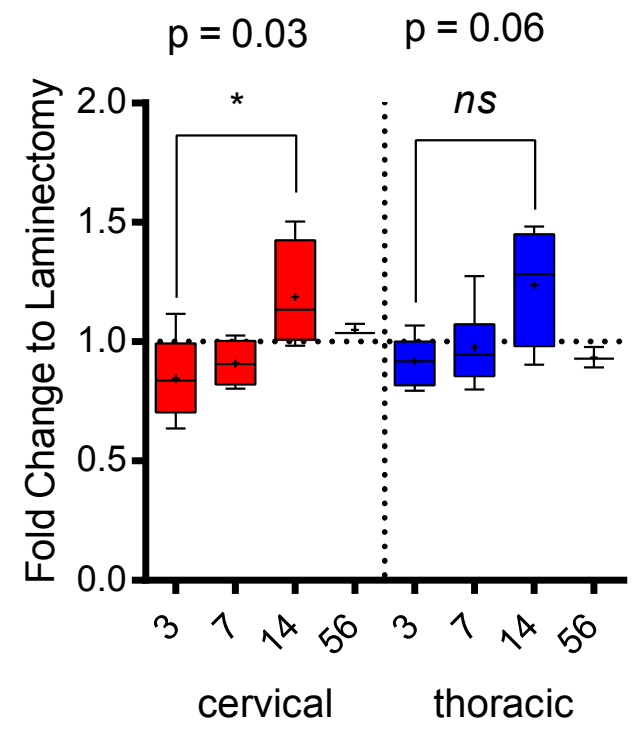

Figure 5. Mass: spleen ratios expressed as fold-change of time-matched laminectomized shams. Error bars represent SEM, and means are indicated by + . A significant change in spleen weight was observed in cSCI between day 3 and day 14 . 


\section{Discussion}

In summary, this is the first study to characterize the temporal plasma expression profile of multiple cytokines, chemokines and growth factors after SCI. It is also the first study to use clinically-relevant models of cSCI and tSCI to determine level-specific differences in the expression of these inflammation-related molecules. This study establishes three main points: (1) time and level-matched laminectomy controls are essential for accurate data interpretation after SCI; (2) there exist both acute and chronic differences in plasma protein expression between CSCI and tSCI; and (3) splenic atrophy is not a robust phenomenon after incomplete $\mathrm{CSCI}$, and as there continues to be evidence of peripheral immune depression after CSCI, it is also not a conclusive diagnostic tool for assessing the state of SCI-IDS.

Inflammation after SCI is considered one of the major drivers of secondary injury and tissue loss, and is often considered a dual-edged sword [30,31]. Our current results examined a small percentage of the cytokine/chemokines/growth factors involved, however, due to the spectrum of cells that secrete these factors, we cannot accurately pinpoint the cellular mediators of the temporal and level-specific changes that we have observed. With regards to the cause of level-differences between laminectomized shams, it is likely they are due to the degree of invasiveness and its associated fibrosis above the site of laminectomy and its differential impact on the cord over time between the two levels.

Studies on five of the six level-distinct proteins have already been conducted in the rodent tSCI model, with IL18 being the only exception with no SCI-associated studies. VEGF is well-known as a potent angiogenic factor that promotes the growth and development of endothelial cells. Our lab was one of the first to study the role of VEGF as a therapeutic agent after acute tSCI [32,33]. In these studies, transcriptionally-enhancing VEGF expression resulted in increased axon preservation, reduced necrosis, and an increase in blood vessels that ultimately translated to increased functional recovery as measured by Catwalk gait analyses. Another study using a contusion tSCI model [34], found that acute intraspinal infusion of VEGF into the lesion epicentre induced autophagy and reduced inflammation in the spinal cord, ultimately resulting in functional recovery as measured by the BBB motor scale. In this study, they showed that VEGF administration reduced the expression of IL1b, IL10 and TNFa in in vitro cultures of LPS-treated neuro-glia co-cultures. In our study, VEGF was upregulated at day 7 relative to $\mathrm{tSCI}$ and this change did indeed coincide with striking systemic reductions in IL1b and IL10. Further, an upregulation of these proteins was observed at 14- and 56-days post-cSCI when VEGF expression returned to baseline. Perhaps one of the major underlying factors of this level-dependent change after $\mathrm{CSCI}$ is the impact of cervical injury on the systemic vasculature as autonomic dysreflexia contributes directly to frequent vascular stress. Overall, there is significant evidence to suggest that VEGF therapy would be effective in both acute $\mathrm{CSCI}$ and $\mathrm{tSCI}$, with the potential to also reduce chronic inflammation in both models.

As a hormone produced mainly by adipose cells, leptin is crucial for energetic balance in the central nervous system. Previous studies into leptin have shown that it is often upregulated both locally and systemically after tSCI [35-37]. While these acute studies were severely limited by the lack of time-matched controls, we observed a striking upregulation of plasma leptin in tSCI, but not cSCI at 1 - and 56-days post-SCI. As leptin is regulated by the sympathetic nervous system, a study has shown that patients with high level SCIs have dysfunctional leptin expression [38] — thus supporting our data. A study [39] that acutely administered purified leptin in a rodent model of tSCI showed increased expression of neuroprotective genes, reduced inflammation and improved BBB, Catwalk and von Frey metrics suggesting that acute and chronic leptin deficiency may be a potent therapeutic target in SCI.

An upregulation in systemic and local IP10 has been demonstrated in both human and rodent SCI [40-42], and while no time-matched controls were used, this upregulation persisted as long as 14 days post-SCI in the murine tSCI model. IP10, is a chemokine secreted by a wide array of immune cells, endothelial cells and fibroblasts in response to IFNg [43]. In our study, IP10 expression was inversely expressed between the two levels, with cSCI experiencing a peak of expression during the subacute phase (days 3-14), and tSCI in the acute and chronic phases (day 1 and 56). Studies that 
neutralized the expression of IP10 showed markedly reduced inflammation, apoptosis, tissue loss and showed modestly improved BBB and BMS outcomes [42,44,45].

While GCSF has had no reported systemic or local expression in the SCI literature, here we find that the expression of GCSF is opposite in CSCI and tSCI. That is, while GCSF is upregulated in $\mathrm{tSCI}$, it is downregulated in CSCI with time-to-time changes also in contrary motion with the exception of day 56. As purified GCSF administration alone and in combination with adipose- and bone-marrow-derived stem and neural stem cells has been shown to be highly beneficial in rodent and human $\mathrm{tSCI}$-including increased tissue preservation, reduced apoptosis and scarring, and improved BBB, BMS and A [46-56] — such a paradigm may prove to be even more effective in the all stages of CSCI where a deficiency in GCSF is seen.

Receptor knockouts of the fractalkine receptor CX3CR1 have resulted in reduced iNOS ${ }^{+} / \mathrm{Ly}^{6} \mathrm{C}^{\text {low }} /$ $\mathrm{MHCII}^{+} / \mathrm{CD} 11 \mathrm{c}^{-}$macrophages and activated microglia that have reduced expression of IL6 and iNOS. In these studies, the authors observed modest improvements in the BMS score [57-59]. In our study, the systemic fractalkine ligand is significantly upregulated in $\mathrm{tSCI}$ at 1-day post-SCI relative to cSCI, with both tSCI and CSCI experiencing late peaks 56-days post-SCI. Fractalkine is present in both a cell-bound and soluble form, and while both forms are potent chemo-attractants for migrating monocytes, the soluble form is also known to attract $\mathrm{T}$ cells. As such, while fractalkine receptor antagonism may be an ideal therapeutic target for acute tSCI, it may also be a valuable target for chronic tSCI and cSCI.

Two potential mechanisms by which CSCI induces an overall decrease in circulating protein are (1) SCI-IDS [20,21] and (2) increased cellular localization (and as such cytokine/chemokines) to the site of injury $[26,28,41]$. SCI-IDS is a phenomenon characterized by rapid splenic atrophy due to repeated bouts of autonomic dysreflexia in higher-level injuries. Interestingly, level-dependent splenic atrophy was not observed between our two incomplete models of cSCI and tSCI (Figure 5). The latter cytokine/chemokine "sink" concept is well-supported by the literature, as recent characterizations of cytokine/chemokine profiles in the spinal cord of SCI rodents and individuals show a striking acute and chronically-persistent expression of many pro- and anti-inflammatory cytokines. This, in conjunction with the increased BSCB permeability after CSCI, may well result in the formation of an inflammatory milieu that can be a potent trigger for secondary injury-especially chronic inflammation. All in all, we have shown striking evidence of level-specific differences in the systemic plasma expression of various cytokines and chemokines. In light of these results, preclinical researchers should adapt time-matched laminectomized controls and consider the impact of anatomical level on the therapeutic target of interest.

\section{Materials and Methods}

All animal experiments were approved by the Animal Care Committee of the University Health Network (Project ID Code: \#2212, Date of Approval: 17 May 2017) in compliance with the Canadian Council on Animal Care.

\subsection{Clip-Compression SCI and Spleen Weight}

Female adult Wistar rats (12-weeks old, 250-300 g, $n=5$ /group for injured, $n=3$ /group for laminectomy and naïve) were used (Charles River Laboratories, Wilmington, MA, USA, http: / /www. criver.com). Prior to surgery, $0.05 \mathrm{mg} / \mathrm{kg}$ of buprenorphine and $5 \mathrm{~mL}$ of saline were administered subcutaneously. $1-2 \%$ of isoflurane in a 1:1 mixture of $\mathrm{O}_{2}$ and $\mathrm{N}_{2} \mathrm{O}$ was used for anesthesia, and a laminectomy was performed at C6-7 and T6-7, respectively. Following this, a moderate-severe injury was induced for 1-min at the cervical or thoracic level as described previously [15,60]. Until the endpoint $(1,3,7,14,56$ days post-SCI), the animals were given subcutaneous buprenorphine $(0.05 \mathrm{mg} / \mathrm{kg}$, bid), oral amoxicillin trihydrate/clavulanate potassium (Apotex Pharmaceuticals, Toronto, ON, Canada) and subcutaneous saline injections $(0.9 \%, 5 \mathrm{~mL}$ sid). Animals were housed individually in cages at $27^{\circ} \mathrm{C}$, and their bladders were manually expressed thrice daily until recovery. 
Prior to sacrifice and perfusion, animal mass and spleens were collected from anesthetized rats and their weight recorded and normalized to their body mass.

\subsection{Neurobehavioural Assessments}

Starting at 7 days post-SCI, weekly forelimb and hindlimb function were assessed with the grip strength meter (SDI Grip Strength System DFM-10, San Diego Instruments, San Diego, CA, USA, http:/ / www.sandiegoinstruments.com) and the BBB Locomotor Rating Scale [61] for cSCI and tSCI, respectively (Figure 6).
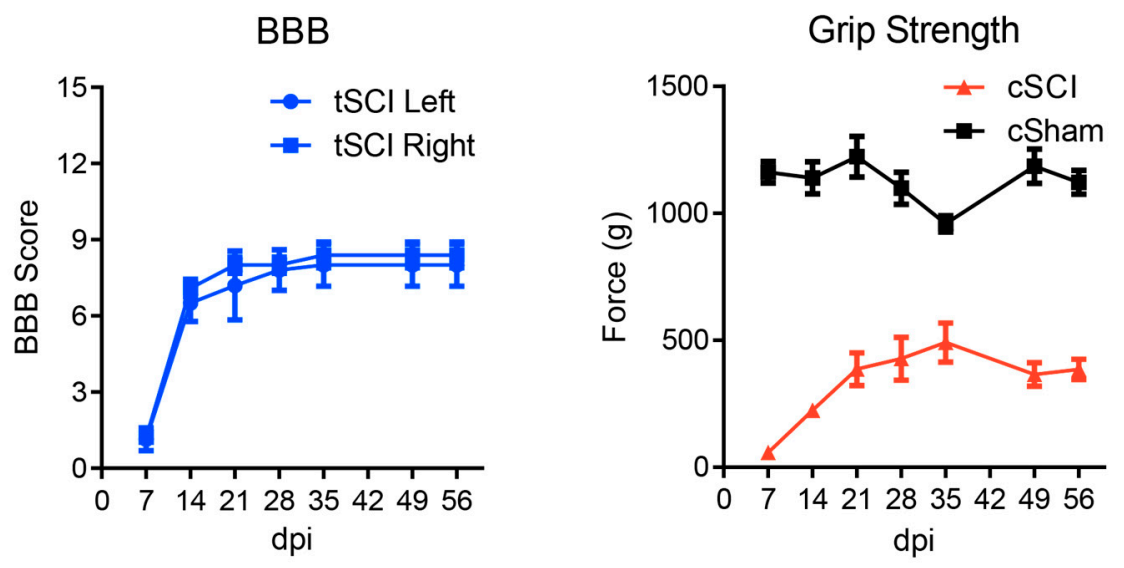

Figure 6. Hindlimb (BBB) and forelimb (Grip strength) assessments following tSCI and cSCI, respectively. No statistical outliers were detected using Grubb's test $(\alpha>0.05)$ indicating good homogeneity of data. Error bars represent SEM.

\subsection{Blood Collection and High-Throughput ELISA}

Blood was collected via a cardiac puncture prior to perfusion using a BD-Vacutainer ${ }^{\circledR}$ Safety-Lok ${ }^{\mathrm{TM}}$ (Franklin Lakes, New Jersey, US) blood collection set containing EDTA. The blood samples were kept on ice and immediately centrifuged at $3000 \mathrm{rpm}$ (Eppendorf 5810R) for $10 \mathrm{~min}$ at $4{ }^{\circ} \mathrm{C}$. The plasma (supernatant) was then carefully aspirated and transferred to a Protein Lo-Bind tube (Eppendorf, Hamburg, Germany). $100 \mu \mathrm{L}$ of the sample was then sent to Eve Technologies (Calgary, AB, Canada, https://www.evetechnologies.com) for high-throughput ELISA profiling using their rat Discovery Assays ${ }^{\mathrm{TM}}$ for cytokine/chemokines (RD27) and vascular injury markers (P1, P2). All proteins that contained interpolated/extrapolated/out-of-range values were removed from the study. The concentration of these proteins was calculated using a standard curve and expressed in $\mathrm{pg} / \mathrm{mL}$.

\subsection{Clustering and Statistical Analysis}

Data are presented as mean \pm SEM and comparisons are presented in order from cervical to thoracic. Heatmap, $k$-means and hierarchical row clustering (1-Cosine Similarity) was performed using the Morpheus software package from the Broad Institute (Cambridge, MA, USA, https:// software.broadinstitute.org/morpheus/). Assessment of normality was performed for each group using the Shapiro-Wilk test of the Rfit package. All protein level comparisons between CSCI and tSCI were performed in GraphPad using either the one-way ANOVA function with post-hoc Sidak's for multiple corrections (parametric, p-adjusted threshold $=0.05$ ) or Krustal-Wallis test with post-hoc Dunn's for multiple corrections (non-parametric, p-adjusted threshold $=0.05$ ). Spleen-body mass ratio comparisons were done in GraphPad using a one-way ANOVA with post-hoc Sidak for multiple corrections (p-adjusted threshold $=0.05$ ). 
Author Contributions: J.H.: conception and design, collection and/or assembly of data, data analysis and interpretation, manuscript writing, final approval of manuscript; A.C.: collection and/or assembly of data, data analysis, final approval of manuscript; M.-M.Z.: collection and/or assembly of data, final approval of manuscript; J.W.: collection and/or assembly of data, final approval of manuscript; Y.L.: collection and/or assembly of data, final approval of manuscript; M.G.F.: conception and design, data analysis and interpretation, financial support, manuscript editing, final approval of manuscript.

Funding: This work was supported by funds from the Unilever/Lipton Graduate Fellowship in Neuroscience (J.H.), the University of Toronto Open Fellowship (J.H.) and the Ontario Graduate Scholarship (J.H.). M.G.F. was supported by the Halbert Chair in Neural Repair and Regeneration and the DeZwirek Family Foundation.

Acknowledgments: We thank Paul Bradshaw and Tim Worden for project management and manuscript review.

Conflicts of Interest: The authors declare no conflict of interest.

\section{Abbreviations}

\begin{tabular}{ll} 
BBB & Basso, Beattie and Bresnahan \\
BMS & Basso Mouse Scale \\
BSCB & Blood-spinal-cord-barrier \\
PBS & Phosphate buffer solution \\
SCI & Spinal cord injury \\
GMCSF & Granulocyte-macrophage colony-stimulating factor \\
IL1a & Interleukin 1 alpha \\
IL1b & Interleukin 1 beta \\
IL2 & Interleukin-2 \\
IL17A & Interleukin-17A \\
IL18 & Interleukin-18 \\
MCP1 & Monocyte chemoattractant protein-1 \\
IP10 & Interferon gamma-induced protein 10 \\
LIX & Lipopolysaccharide-induced CXC chemokine \\
MIP2 & macrophage inflammatory protein 2 \\
RANTES & regulated on activation, normal T cell expressed and secreted \\
GCSF & Granulocyte-colony stimulating factor \\
IL4 & Interleukin-4 \\
IL10 & Interleukin-10 \\
IL12 & Interleukin-12 \\
IL5 & Interleukin-5 \\
IFNg & Interferon gamma \\
VEGF & Vascular endothelial growth factor \\
& \\
\hline
\end{tabular}

\section{References}

1. Ahuja, C.S.; Wilson, J.R.; Nori, S.; Kotter, M.R.N.; Druschel, C.; Curt, A.; Fehlings, M.G. Traumatic spinal cord injury. Nat. Rev. Dis. Primers 2017, 3, 17018. [CrossRef] [PubMed]

2. Tator, C.H.; Fehlings, M.G. Review of the secondary injury theory of acute spinal cord trauma with emphasis on vascular mechanisms. J. Neurosurg. 1991, 75, 15-26. [CrossRef] [PubMed]

3. Tator, C.H.; Koyanagi, I. Vascular mechanisms in the pathophysiology of human spinal cord injury. J. Neurosurg. 1997, 86, 483-492. [CrossRef] [PubMed]

4. Figley, S.A.; Khosravi, R.; Legasto, J.M.; Tseng, Y.-F.; Fehlings, M.G. Characterization of vascular disruption and blood-spinal cord barrier permeability following traumatic spinal cord injury. J. Neurotrauma 2014, 31, 541-552. [CrossRef] [PubMed]

5. Rothstein, J.D.; Dykes-Hoberg, M.; Pardo, C.A.; Kanai, Y.; Bristol, L.A.; Kuncl, R.W.; Welty, D.F.; Jin, L.; Hediger, M.A.; Wang, Y.; et al. Knockout of Glutamate Transporters Reveals a Major Role for Astroglial Transport in Excitotoxicity and Clearance of Glutamate. Neuron 1996, 16, 675-686. [CrossRef]

6. Agrawal, S.K.; Fehlings, M.G. Role of NMDA and Non-NMDA Ionotropic Glutamate Receptors in Traumatic Spinal Cord Axonal Injury. J. Neurosci. 1997, 17, 1055-1063. [CrossRef] [PubMed] 
7. Braughler, J.M.; Duncan, L.A.; Chase, R.L. Interaction of lipid peroxidation and calcium in the pathogenesis of neuronal injury. Cent. Nerv. Syst. Trauma 1985, 2, 269-283. [CrossRef] [PubMed]

8. Diaz-Ruiz, A.; Rios, C.; Duarte, I.; Correa, D.; Guizar-Sahagun, G.; Grijalva, I.; Ibarra, A. Cyclosporin-A inhibits lipid peroxidation after spinal cord injury in rats. Neurosci. Lett. 1999, 266, 61-64. [CrossRef]

9. Kaptanoglu, E.; Solaroglu, I.; Okutan, O.; Surucu, H.S.; Akbiyik, F.; Beskonakli, E. Erythropoietin exerts neuroprotection after acute spinal cord injury in rats: Effect on lipid peroxidation and early ultrastructural findings. Neurosurg. Rev. 2004, 27, 113-120. [CrossRef] [PubMed]

10. Winkler, E.A.; Sengillo, J.D.; Bell, R.D.; Wang, J.; Zlokovic, B.V. Blood-spinal cord barrier pericyte reductions contribute to increased capillary permeability. J. Cereb. Blood Flow Metab. 2012, 32, 1841-1852. [CrossRef] [PubMed]

11. Whetstone, W.D.; Hsu, J.-Y.C.; Eisenberg, M.; Werb, Z.; Noble-Haeusslein, L.J. Blood-spinal cord barrier after spinal cord injury: Relation to revascularization and wound healing. J. Neurosci. Res. 2003, 74, 227-239. [CrossRef] [PubMed]

12. Noble, L.J.; Wrathall, J.R. Blood-spinal cord barrier disruption proximal to a spinal cord transection in the rat: Time course and pathways associated with protein leakage. Exp. Neurol. 1988, 99, 567-578. [CrossRef]

13. Fehlings, M.G.; Agrawal, S. Role of sodium in the pathophysiology of secondary spinal cord injury. Spine 1995, 20, 2187-2191. [CrossRef] [PubMed]

14. Schwartz, G.; Fehlings, M.G. Evaluation of the neuroprotective effects of sodium channel blockers after spinal cord injury: Improved behavioral and neuroanatomical recovery with riluzole. J. Neurosurg. Spine 2001, 94, 245-256. [CrossRef]

15. Wilcox, J.T.; Satkunendrarajah, K.; Nasirzadeh, Y.; Laliberte, A.M.; Lip, A.; Cadotte, D.W.; Foltz, W.D.; Fehlings, M.G. Generating level-dependent models of cervical and thoracic spinal cord injury: Exploring the interplay of neuroanatomy, physiology, and function. Neurobiol. Dis. 2017, 105, 194-212. [CrossRef] [PubMed]

16. Ulndreaj, A.; Badner, A.; Fehlings, M.G. Promising neuroprotective strategies for traumatic spinal cord injury with a focus on the differential effects among anatomical levels of injury. F1000Res 2017, 6, 1907. [CrossRef] [PubMed]

17. Zhang, Y.; Guan, Z.; Reader, B.; Shawler, T.; Mandrekar-Colucci, S.; Huang, K.; Weil, Z.; Bratasz, A.; Wells, J.; Powell, N.D.; et al. Autonomic Dysreflexia Causes Chronic Immune Suppression after Spinal Cord Injury. J. Neurosci. 2013, 33, 12970-12981. [CrossRef] [PubMed]

18. Lucin, K.M.; Sanders, V.M.; Popovich, P.G. Stress hormones collaborate to induce lymphocyte apoptosis after high level spinal cord injury. J. Neurochem. 2009, 110, 1409-1421. [CrossRef] [PubMed]

19. Partida, E.; Mironets, E.; Hou, S.; Tom, V.J. Cardiovascular dysfunction following spinal cord injury. Neural Regen. Res. 2016, 11, 189-194. [PubMed]

20. Brommer, B.; Engel, O.; Kopp, M.A.; Watzlawick, R.; Müller, S.; Prüss, H.; Chen, Y.; DeVivo, M.J.; Finkenstaedt, F.W.; Dirnagl, U.; et al. Spinal cord injury-induced immune deficiency syndrome enhances infection susceptibility dependent on lesion level. Brain 2016, 139, 692-707. [CrossRef] [PubMed]

21. Schwab, J.M.; Zhang, Y.; Kopp, M.A.; Brommer, B.; Popovich, P.G. The paradox of chronic neuroinflammation, systemic immune suppression, autoimmunity after traumatic chronic spinal cord injury. Exp. Neurol. 2014, 258, 121-129. [CrossRef] [PubMed]

22. Waykole, Y.P.; Doiphode, S.S.; Rakhewar, P.S.; Mhaske, M. Anticytokine therapy for periodontal diseases: Where are we now? J. Indian Soc. Periodontol. 2009, 13, 64-68. [CrossRef] [PubMed]

23. Audet, M.-C.; Anisman, H. Interplay between pro-inflammatory cytokines and growth factors in depressive illnesses. Front. Cell. Neurosci. 2013, 7, 68. [CrossRef] [PubMed]

24. Kofler, S.; Nickel, T.; Weis, M. Role of cytokines in cardiovascular diseases: A focus on endothelial responses to inflammation. Clin. Sci. 2005, 108, 205-213. [CrossRef] [PubMed]

25. Mukhamedshina, Y.O.; Akhmetzyanova, E.R.; Martynova, E.V.; Khaiboullina, S.F.; Galieva, L.R.; Rizvanov, A.A. Systemic and Local Cytokine Profile following Spinal Cord Injury in Rats: A Multiplex Analysis. Front. Neurol. 2017, 8, 581. [CrossRef] [PubMed]

26. Bartholdi, D.; Schwab, M.E. Expression of pro-inflammatory cytokine and chemokine mRNA upon experimental spinal cord injury in mouse: An in situ hybridization study. Eur. J. Neurosci. 1997, 9, 1422-1438. [CrossRef] [PubMed] 
27. Klusman, I.; Schwab, M.E. Effects of pro-inflammatory cytokines in experimental spinal cord injury. Brain Res. 1997, 762, 173-184. [CrossRef]

28. Schnell, L.; Fearn, S.; Schwab, M.E.; Perry, V.H.; Anthony, D.C. Cytokine-induced acute inflammation in the brain and spinal cord. J. Neuropathol. Exp. Neurol. 1999, 58, 245-254. [CrossRef] [PubMed]

29. Francos Quijorna, I.; Santos-Nogueira, E.; Gronert, K.; Sullivan, A.B.; Kopp, M.A.; Brommer, B.; David, S.; Schwab, J.M.; Lopez Vales, R. Maresin 1 promotes inflammatory resolution, neuroprotection and functional neurological recovery after spinal cord injury. J. Neurosci. 2017, 29, 11731-11743. [CrossRef] [PubMed]

30. Anderson, A.J.; Robert, S.; Huang, W.; Young, W.; Cotman, C.W. Activation of complement pathways after contusion-induced spinal cord injury. J. Neurotrauma 2004, 21, 1831-1846. [CrossRef] [PubMed]

31. Kasinathan, N.; Vanathi, M.B.; Subrahmanyam, V.M.; Rao, J.V. A review on response of immune system in spinal cord injury and therapeutic agents useful in treatment. Curr. Pharm. Biotechnol. 2015, 16, 26-34. [CrossRef] [PubMed]

32. Figley, S.A.; Liu, Y.; Karadimas, S.K.; Satkunendrarajah, K.; Fettes, P.; Spratt, S.K.; Lee, G.; Ando, D.; Surosky, R.; Giedlin, M.; et al. Delayed administration of a bio-engineered zinc-finger VEGF-A gene therapy is neuroprotective and attenuates allodynia following traumatic spinal cord injury. PLoS ONE 2014, 9, e96137. [CrossRef] [PubMed]

33. Liu, Y.; Figley, S.; Spratt, S.K.; Lee, G.; Ando, D.; Surosky, R.; Fehlings, M.G. An engineered transcription factor which activates VEGF-A enhances recovery after spinal cord injury. Neurobiol. Dis. 2010, 37, 384-393. [CrossRef] [PubMed]

34. Wang, H.; Wang, Y.; Li, D.; Liu, Z.; Zhao, Z.; Han, D.; Yuan, Y.; Bi, J.; Mei, X. VEGF inhibits the inflammation in spinal cord injury through activation of autophagy. Biochem. Biophys. Res. Commun. 2015, 464, 453-458. [CrossRef] [PubMed]

35. Wang, L.; Tang, X.; Zhang, H.; Yuan, J.; Ding, H.; Wei, Y. Elevated leptin expression in rat model of traumatic spinal cord injury and femoral fracture. J. Spinal Cord Med. 2011, 34, 501-509. [CrossRef] [PubMed]

36. Gezici, A.R.; Ergun, R.; Karakas, A.; Gunduz, B. Serum leptin levels following acute experimental spinal cord injury. J. Spinal Cord Med. 2009, 32, 416-421. [CrossRef] [PubMed]

37. Garshick, E.; Walia, P.; Goldstein, R.L.; Teylan, M.; Lazzari, A.A.; Tun, C.G.; Hart, J.E. Plasma Leptin and Reduced FEV1 and FVC in Chronic Spinal Cord Injury. PM R 2017, 10, 276-285. [CrossRef] [PubMed]

38. Jeon, J.Y.; Steadward, R.D.; Wheeler, G.D.; Bell, G.; McCargar, L.; Harber, V. Intact sympathetic nervous system is required for leptin effects on resting metabolic rate in people with spinal cord injury. J. Clin. Endocrinol. Metab. 2003, 88, 402-407. [CrossRef] [PubMed]

39. Fernández-Martos, C.M.; González, P.; Rodriguez, F.J. Acute leptin treatment enhances functional recovery after spinal cord injury. PLoS ONE 2012, 7, e35594. [CrossRef] [PubMed]

40. Kwon, B.K.; Streijger, F.; Fallah, N.; Noonan, V.K.; Bélanger, L.M.; Ritchie, L.; Paquette, S.J.; Ailon, T.; Boyd, M.C.; Street, J.; et al. Cerebrospinal Fluid Biomarkers To Stratify Injury Severity and Predict Outcome in Human Traumatic Spinal Cord Injury. J. Neurotrauma 2017, 34, 567-580. [CrossRef] [PubMed]

41. Lee, Y.L.; Shih, K.; Bao, P.; Ghirnikar, R.S.; Eng, L.F. Cytokine chemokine expression in contused rat spinal cord. Neurochem. Int. 2000, 36, 417-425. [CrossRef]

42. Glaser, J.; Gonzalez, R.; Sadr, E.; Keirstead, H.S. Neutralization of the chemokine CXCL10 reduces apoptosis and increases axon sprouting after spinal cord injury. J. Neurosci. Res. 2006, 84, 724-734. [CrossRef] [PubMed]

43. Di Lernia, V. Targeting the IFN- $\gamma /$ CXCL10 pathway in lichen planus. Med. Hypotheses 2016, 92, 60-61. [CrossRef] [PubMed]

44. Glaser, J.; Gonzalez, R.; Perreau, V.M.; Cotman, C.W.; Keirstead, H.S. Neutralization of the chemokine CXCL10 enhances tissue sparing and angiogenesis following spinal cord injury. J. Neurosci. Res. 2004, 77, 701-708. [CrossRef] [PubMed]

45. Gonzalez, R.; Hickey, M.J.; Espinosa, J.M.; Nistor, G.; Lane, T.E.; Keirstead, H.S. Therapeutic neutralization of CXCL10 decreases secondary degeneration and functional deficit after spinal cord injury in mice. Regen. Med. 2007, 2, 771-783. [CrossRef] [PubMed]

46. Min, J.; Kim, J.H.; Choi, K.H.; Yoon, H.H.; Jeon, S.R. Is There Additive Therapeutic Effect When GCSF Combined with Adipose-Derived Stem Cell in a Rat Model of Acute Spinal Cord Injury? J. Korean Neurosurg. Soc. 2017, 60, 404-416. [CrossRef] [PubMed] 
47. Nishio, Y.; Koda, M.; Kamada, T.; Someya, Y.; Kadota, R.; Mannoji, C.; Miyashita, T.; Okada, S.; Okawa, A.; Moriya, H.; et al. Granulocyte colony-stimulating factor attenuates neuronal death and promotes functional recovery after spinal cord injury in mice. J. Neuropathol. Exp. Neurol. 2007, 66, 724-731. [CrossRef] [PubMed]

48. Kato, K.; Koda, M.; Takahashi, H.; Sakuma, T.; Inada, T.; Kamiya, K.; Ota, M.; Maki, S.; Okawa, A.; Takahashi, K.; et al. Granulocyte colony-stimulating factor attenuates spinal cord injury-induced mechanical allodynia in adult rats. J. Neurol. Sci. 2015, 355, 79-83. [CrossRef] [PubMed]

49. Dittgen, T.; Pitzer, C.; Plaas, C.; Kirsch, F.; Vogt, G.; Laage, R.; Schneider, A. Granulocyte-colony stimulating factor (G-CSF) improves motor recovery in the rat impactor model for spinal cord injury. PLoS ONE 2012, 7, e29880. [CrossRef] [PubMed]

50. Kadota, R.; Koda, M.; Kawabe, J.; Hashimoto, M.; Nishio, Y.; Mannoji, C.; Miyashita, T.; Furuya, T.; Okawa, A.; Takahashi, K.; et al. Granulocyte colony-stimulating factor (G-CSF) protects oligodendrocyte and promotes hindlimb functional recovery after spinal cord injury in rats. PLoS ONE 2012, 7, e50391. [CrossRef] [PubMed]

51. Guo, Y.; Liu, S.; Wang, P.; Zhang, H.; Wang, F.; Bing, L.; Gao, J.; Yang, J.; Hao, A. Granulocyte colony-stimulating factor improves neuron survival in experimental spinal cord injury by regulating nucleophosmin-1 expression. J. Neurosci. Res. 2014, 92, 751-760. [CrossRef] [PubMed]

52. Koda, M.; Nishio, Y.; Kamada, T.; Someya, Y.; Okawa, A.; Mori, C.; Yoshinaga, K.; Okada, S.; Moriya, H.; Yamazaki, M. Granulocyte colony-stimulating factor (G-CSF) mobilizes bone marrow-derived cells into injured spinal cord and promotes functional recovery after compression-induced spinal cord injury in mice. Brain Res. 2007, 1149, 223-231. [CrossRef] [PubMed]

53. Lee, J.-S.; Yang, C.-C.; Kuo, Y.-M.; Sze, C.-I.; Hsu, J.-Y.C.; Huang, Y.-H.; Tzeng, S.-F.; Tsai, C.-L.; Chen, H.-H.; Jou, I.-M. Delayed granulocyte colony-stimulating factor treatment promotes functional recovery in rats with severe contusive spinal cord injury. Spine 2012, 37, 10-17. [CrossRef] [PubMed]

54. Takahashi, H.; Yamazaki, M.; Okawa, A.; Sakuma, T.; Kato, K.; Hashimoto, M.; Hayashi, K.; Furuya, T.; Fujiyoshi, T.; Kawabe, J.; et al. Neuroprotective therapy using granulocyte colony-stimulating factor for acute spinal cord injury: A phase I/IIa clinical trial. Eur. Spine J. 2012, 21, 2580-2587. [CrossRef] [PubMed]

55. Kamiya, K.; Koda, M.; Furuya, T.; Kato, K.; Takahashi, H.; Sakuma, T.; Inada, T.; Ota, M.; Maki, S.; Okawa, A.; et al. Neuroprotective therapy with granulocyte colony-stimulating factor in acute spinal cord injury: A comparison with high-dose methylprednisolone as a historical control. Eur. Spine J. 2015, 24, 963-967. [CrossRef] [PubMed]

56. Yoon, S.H.; Shim, Y.S.; Park, Y.H.; Chung, J.K.; Nam, J.H.; Kim, M.O.; Park, H.C.; Park, S.R.; Min, B.-H.; Kim, E.Y.; et al. Complete Spinal Cord Injury Treatment Using Autologous Bone Marrow Cell Transplantation and Bone Marrow Stimulation with Granulocyte Macrophage-Colony Stimulating Factor: Phase I/II Clinical Trial. Stem Cells 2007, 25, 2066-2073. [CrossRef] [PubMed]

57. Poniatowski, Ł.A.; Wojdasiewicz, P.; Krawczyk, M.; Szukiewicz, D.; Gasik, R.; Kubaszewski, Ł.; Kurkowska-Jastrzębska, I. Analysis of the Role of CX3CL1 (Fractalkine) and Its Receptor CX3CR1 in Traumatic Brain and Spinal Cord Injury: Insight into Recent Advances in Actions of Neurochemokine Agents. Mol. Neurobiol. 2017, 54, 2167-2188. [CrossRef] [PubMed]

58. Donnelly, D.J.; Longbrake, E.E.; Shawler, T.M.; Kigerl, K.A.; Lai, W.; Tovar, C.A.; Ransohoff, R.M.; Popovich, P.G. Deficient CX3CR1 signaling promotes recovery after mouse spinal cord injury by limiting the recruitment and activation of Ly6Clo/iNOS+ macrophages. J. Neurosci. 2011, 31, 9910-9922. [CrossRef] [PubMed]

59. Freria, C.M.; Hall, J.C.E.; Wei, P.; Guan, Z.; McTigue, D.M.; Popovich, P.G. Deletion of the Fractalkine Receptor, CX3CR1, Improves Endogenous Repair, Axon Sprouting, and Synaptogenesis after Spinal Cord Injury in Mice. J. Neurosci. 2017, 37, 3568-3587. [CrossRef] [PubMed]

60. Wilcox, J.T.; Fehlings, M.G. Acute Clip Compression Model of SCI. In Experimental Neurosurgery in Animal Models; Neuromethods; Springer: New York, NY, USA, 2016; Volume 116, pp. 111-117.

61. Basso, D.M.; Beattie, M.S.; Bresnahan, J.C. A Sensitive and Reliable Locomotor Rating Scale for Open Field Testing in Rats. J. Neurotrauma 1995, 12, 1-21. [CrossRef] [PubMed]

(C) 2018 by the authors. Licensee MDPI, Basel, Switzerland. This article is an open access article distributed under the terms and conditions of the Creative Commons Attribution (CC BY) license (http:/ / creativecommons.org/licenses/by/4.0/). 